(c) 2020, The Authors. Published by FASS Inc. and Elsevier Inc. on behalf of the American Dairy Science Association ${ }^{\circledR}$. This is an open access article under the CC BY-NC-ND license (http://creativecommons.org/licenses/by-nc-nd/4.0/).

\title{
Technical note: Droplet digital PCR precisely and accurately quantifies sex skew in bovine semen
}

\author{
Nicole Cray, ${ }^{1} \oplus$ Matthias Wagner, ${ }^{2}$ Jami Hauer, ${ }^{1} \oplus$ and Elon Roti Roti ${ }^{1 *}{ }^{1} \odot$ \\ ${ }^{1}$ GenusPlc, ABS Global, 6308 Pepsi Way, Windsor, WI 53598 \\ ${ }^{2}$ Cellino Biotech Inc., 14 Mellen St., Cambridge, MA 02138
}

\section{ABSTRACT}

Quantifying the relative population of sperm cells bearing the $\mathrm{X}$ or $\mathrm{Y}$ chromosome in a sexed-semen sample has historically been limited to methods that are either low throughput and sensitive to user subjectivity (e.g., fluorescence in situ hybridization), conterminous (using the same technology to generate and confirm the sex skew), or relatively insensitive (including quantitative PCR with a change detection threshold of $2 \times$ ). Customers pay a premium for sexed semen and should have access to reliable sex skew data, generated by an accurate, precise test that is orthogonal to the method used to generate sexed semen. Droplet digital PCR (ddPCR) has the capacity to provide an accurate and precise sex skew quantitation by subdividing a pool of template DNA into nanoliter-scale droplets containing either 1 or 0 copies of template DNA. Then PCR amplification is conducted in the droplets, and the number of copies of the amplicon of interest can be counted as the number of fluorescence-positive droplets based on classic quantitative PCR fluorescent reporters. We have optimized and validated a multiplexed ddPCR assay that uses this copy counting method to quantify the sex skew (ratio of X or Y chromosomes) in frozenthawed bovine sexed semen. The assay interrogates at least 1,000 cells per sample well, quantifying $\mathrm{X}$ and $\mathrm{Y}$ chromosome copy numbers along with an autosomal gene, GAPDH, used as an internal assay control to confirm total cells counted. The ddPCR sex skew assay achieved a 0.5 -percentage-point variance for $\% \mathrm{X}$ or $\% \mathrm{Y}$ with a broad linear detection range, from 10 to $95 \% \mathrm{X}$, and provided reproducible skew values across a range of 9 to $27 \mathrm{ng}$ of genomic DNA input. This approach overcomes some limitations of other sex skew assays by quantifying absolute $\mathrm{X}$ and $\mathrm{Y}$ chromosome copy numbers, thus providing a rigorous, independent assessment of sex-skewed semen.

Received November 8, 2019.

Accepted February 28, 2020.

*Corresponding author: elon.rotiroti@genusplc.com
Key words: sexed semen, dairy, droplet digital PCR (ddPCR)

\section{Technical Note}

Dairy farmers increase profitability by utilizing X-enriched or "skewed" sexed semen from sires with desired genetic traits to maintain a high-quality milkproducing herd. The utility of sexed semen depends upon the percentage of $\mathrm{X}$ - and Y-chromosome-bearing sperm ("female" or "male" cells) present in the product, which in turn depends on the accuracy of both making sexed semen and verifying the final sex skew. To produce commercial sexed semen, sperm are stained with Hoechst 33342, which binds stoichiometrically to DNA (Lalande and Miller, 1979) and emits a fluorescent signal, which allows cytometers to discriminate $\mathrm{X}$ - and Y-chromosome-containing sperm based on the $\sim 4 \%$ difference in total DNA content between the X and Y chromosomes (Moruzzi, 1979; Johnson, 1995; van Munster et al., 1999). Sperm may then be segregated into separate containers based on sex (Johnson and Welch, 1999) or the cells of the undesired sex are laser-ablated (Faust et al., 2016). Given the inherent challenges of separating 2 cell populations based on a $4 \%$ DNA content difference (Seidel, 2014), the maximum achievable sex skew is variable and depends upon how well the sperm are stained, how well they are aligned in the optical detection plane, and on the sperm flow rate through the cytometer (Johnson and Welch, 1999). Field performance indicates that X-skewed sexed-semen inseminations produce 86 to $93 \%$ female calves (Cerchiaro et al., 2007; Borchersen and Peacock, 2009; Norman et al., 2010; Healy et al., 2013), likely reflecting the inherent variance of X-skewed sexed semen.

Bovine semen sex skew is commonly determined by requantification using the same cytometers used to manufacture the sexed semen (Seidel, 2014), though available orthogonal methods include fluorescence in situ hybridization (FISH) and quantitative PCR (qPCR). Each approach has advantages and limitations. Semen-sexing cytometers quantify sex skew using 
the same DNA-binding dye and detection scheme that originally generated the sexed semen, rather than an independent test; the skew data are therefore subject to the same variations or biases as manufacturing the sexskewed product and are limited by the lack of unique, positive identifiers for the $\mathrm{X}$ and $\mathrm{Y}$ chromosomes. The FISH and qPCR approaches both specifically identify $\mathrm{X}$ and $\mathrm{Y}$ chromosomes (Kawarasaki et al., 1998; Rens et al., 2001; Habermann et al., 2005; Parati et al., 2006; Puglisi et al., 2006; Khamlor et al., 2014), but lack quantitative sensitivity and statistical rigor due to sampling (FISH) and sensitivity (qPCR) limitations. In an effort to overcome these challenges, we present methods for a droplet digital PCR (ddPCR) sex skew assay that quantifies total X and Y chromosome copies, reporting sex skew as a percentage with a variance of \pm 0.5 percentage point. The numbers of $\mathrm{X}$ and $\mathrm{Y}$ chromosome copies are quantified independently in a multiplex reaction, along with an autosomal amplicon to confirm the total number of cells represented in the assay as an internal assay control. The methods have been filed for patent and can be found at http://appft .uspto.gov $/$ netacgi $/$ nph-Parser?Sect1=PTO2\&Sect2= HITOFF \&p $=1 \& u=\% 2$ Fnetahtml $\% 2$ FPTO $\% 2$ Fsearch -bool.html\&r=1\&f=G\&l=50\&co1=AND\&d=PG01\& $\mathrm{s} 1=\% 2216 \% 2 \mathrm{~F} 121,077 \% 22 \& \mathrm{OS}=\% 2216 / 121,077 \% 22 \&$ $\mathrm{RS}=\% 2216 / 121,077 \% 22$ (Roti Roti et al., 2018).

Assay development began with screening primer combinations via standard PCR, followed by assessing reproducibility in qPCR, and ultimately testing quantitative reproducibility in ddPCR, as summarized in Figure 1. To develop a robust sex skew assay, intron/ exon spanning primer pairs were designed based on the Bos_taurus_UMD_3.1.1 Assembly (https://www.ncbi .nlm.nih.gov/assembly/GCF_000003055.6/). Supplemental Table S1 (https://doi.org/10.3168/jds.2019 -17877) details the primer pairs screened, including amplicons on the $\mathrm{X}$ and $\mathrm{Y}$ chromosomes, along with several autosomal genes targeted based on published qPCR data. Primer combinations that consistently generated PCR product of the predicted molecular weight across genomic DNA samples from 16 unique sires, including Holstein, Jersey, and Angus breeds (data not shown), were evaluated for efficiency and reproducibility with their respective probes using qPCR. Primer combinations that failed even once to produce robust bands of the predicted molecular weight from all sires tested were eliminated from further assay development, because an assay designed for screening a commercial product must be insensitive to genetic variation inherent in any population. These primer combinations included HMBS, PRLPO, TBP, $\mathrm{X}_{1}, \mathrm{X}_{3}$, and $\mathrm{Y}_{5}$.

The next criteria to develop primers and probes for the ddPCR sex skew assay required each primer/probe set to produce a qPCR cycle threshold (CT) value (the number of thermocycles it takes for the fluorescent signal to become greater than the background threshold) between 15 and 35 , with a variance of $<0.5 \mathrm{CT}$, as expected for a high-abundance gene. Probes used Taqman chemistry (Heid et al., 1996) with either FAM or HEX fluorescent tags and are listed in Supplemental Table S1 (https://doi.org/10.3168/jds.2019-17877). A $20-\mu \mathrm{L}$ qPCR reaction contained $10 \mu \mathrm{L}$ of Bullseye TaqProbe qPCR MasterMix (MidSci, St. Louis, MO), 1 $\mu \mathrm{L}$ of each $10 \mu M$ forward and reverse primer, $1.5 \mu \mathrm{L}$ of $2 \mu M$ probe, and $5 \mu \mathrm{L}$ of genomic DNA. Samples were thermocycled in a PrimePro48 Real-Time PCR System (Techne/Cole-Parmer, Stone, UK) as follows: $10 \mathrm{~min}$ at $95^{\circ} \mathrm{C}$ and 40 cycles of $\left(15 \mathrm{~s}\right.$ at $95^{\circ} \mathrm{C}, 60 \mathrm{~s}$ at $\left.60^{\circ} \mathrm{C}\right)$. Data were analyzed using Techne Pro and ProStudy (Cole-Parmer). Supplemental Figure S1A (https:// doi.org/10.3168/jds.2019-17877) plots the mean CT values and Figure 2B plots the standard deviation of the CT values for each candidate autosomal primer/ probe combination. Although all candidate amplicons exhibited absolute $\mathrm{CT}$ values in the acceptable range (Supplemental Figure S1A), ACT2B and HPRT1 amplicons exhibited variance outside the acceptance criteria (Supplemental Figure S1B, $\mathrm{n}=7$ sires) and were eliminated from further assay development. Similarly, Supplemental Figure S1 panels C and D plot the mean $\mathrm{CT}$ values and standard deviations for 2 candidate $\mathrm{X}$ and Y-chromosome amplicons, all of which met requirements for $\mathrm{CT}$ value and variance. These data identified candidate primer/probe combinations for ddPCR that exhibited minimal variance across individual genomic DNA templates, and limited further assay development to candidate autosomal amplicons for GAPDH and B2M, which both met requirements in the $\mathrm{qPCR}$ reactions.

To use an autosomal amplicon as a cell counting tool, the amplicon should report the predicted copy number in a 1:1 relationship across a range of DNA input amounts (ng). The reported copy numbers for GAPDH and $B 2 M$ were evaluated in singleplex ddPCR reactions to determine which provided a more accurate cell counting tool with tight correlation to the predicted copy number based on bovine genomic molecular weight, input DNA amount (ng), and the haploid nature of sperm cells. Predicted copies per ddPCR reaction was calculated as follows:

$$
\begin{gathered}
\text { Amount of genomic template }(\mathrm{ng}) \\
\times\{[\text { Avogadro's number }(\text { molecules } / \mathrm{mol})] / \\
{[\text { genomic length }(\mathrm{bp})} \\
\left.\left.\times \text { MW per base pair }(\mathrm{Da}) \times 10^{8}\right]\right\},
\end{gathered}
$$


using the Bos taurus genomic molecular weight obtained from https://uswest.ensembl.org/Bos_taurus/ Info/Annotation, which used the UMD 3.1 INSDC Assembly GCA_000003055.3, Nov 2009, referencing a total of 2,649,685,036 bp in the Bos taurus genome. Although GAPDH copy counts reflected nanograms of input DNA in a 1:1 ratio, B2M consistently reported twice the predicted copy number (data not shown) and was therefore excluded from further assay development.

The sex skew assay was designed to interrogate one target each on the $\mathrm{X}$ and $\mathrm{Y}$ chromosomes as well as an autosomal target to confirm the total cells counted. The assay was developed using the Bio-Rad Droplet Digital Reader (Bio-Rad Laboratories, Hercules, CA),

\section{Standard PCR with Gel Electrophoresis}

Successful primers:

- Produced amplicons of predicted molecular weight from all template samples

- Did not produce product in the absence of template or when paired with noncorresponding primers

Successful primers / probe combinations:

- Produced signal above background only when paired with primers/probes against same amplicon

- Produce CT value $>15$ and $<35$ with variance of $>0.5 \mathrm{CT}$ across different templates

\section{2. $\mathrm{qPCR}$}

\section{C.5}

\section{3. ddPCR Sex Skew Assay}

Primers and/or Probes that did not meet assay requirements at each step were eliminated from further development.

Successful autosomal primer/probe combinations:

- Total copies counted per reaction match predicted copy numbers across a range of ng DNA template inputs

Successful sex chromosome primer/probe combinations:

- Sum of sex chromosomes counted per reaction matches autosomal copies counted within variance

Successful multiplex assay conditions:

- Variance in calculating $\% X$ chromosome in repeat measures $<1$ percent point

- Assay interrogates at least 1000 cells per well

- When creating deliberate ratios of $X$ and $Y$ in samples, the assay reports predicted $X$ skew across the entire dose-response range

Figure 1. Schematic depicting the assay development pipeline and primer/probe screening for the droplet digital PCR (ddPCR) sex skew assay. qPCR = quantitative PCR; CT = cycle threshold. 
however, which limits detection to 2 fluorophores and creates a challenge in identifying 3 unique targets. Optimizing a triplex ddPCR assay required maximizing the fluorescent signal separation of the droplet populations, which may contain only individual target amplicons (X, $\mathrm{Y}$, or $G A P D H)$, or any combination of the 3 targets $(\mathrm{X}+\mathrm{Y}, \mathrm{X}+G A P D H, \mathrm{Y}+G A P D H$, and $\mathrm{X}+\mathrm{Y}+G A P D H)$. Two amplicons can be discretely identified, 1 in each of the 2 fluorescent channels, when utilizing HEX and
FAM probes separately for the 2 targets. The third amplicon must be detected using a mix of 2 probes that are identical in sequence but differentially tagged with either the HEX or FAM fluorophore (Figure 2A). Input quantities for template genomic DNA and each primer and probe were iteratively adjusted to achieve maximal separation of the fluorescent droplet populations while assaying the maximal total number of cells. The final validated assay conditions used $900 \mathrm{n} M$ primer with
A

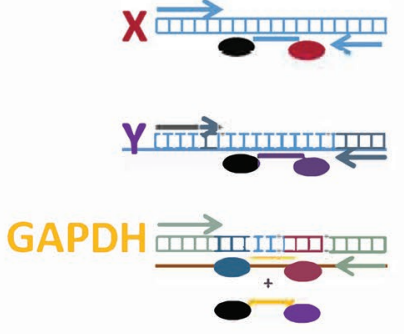

B

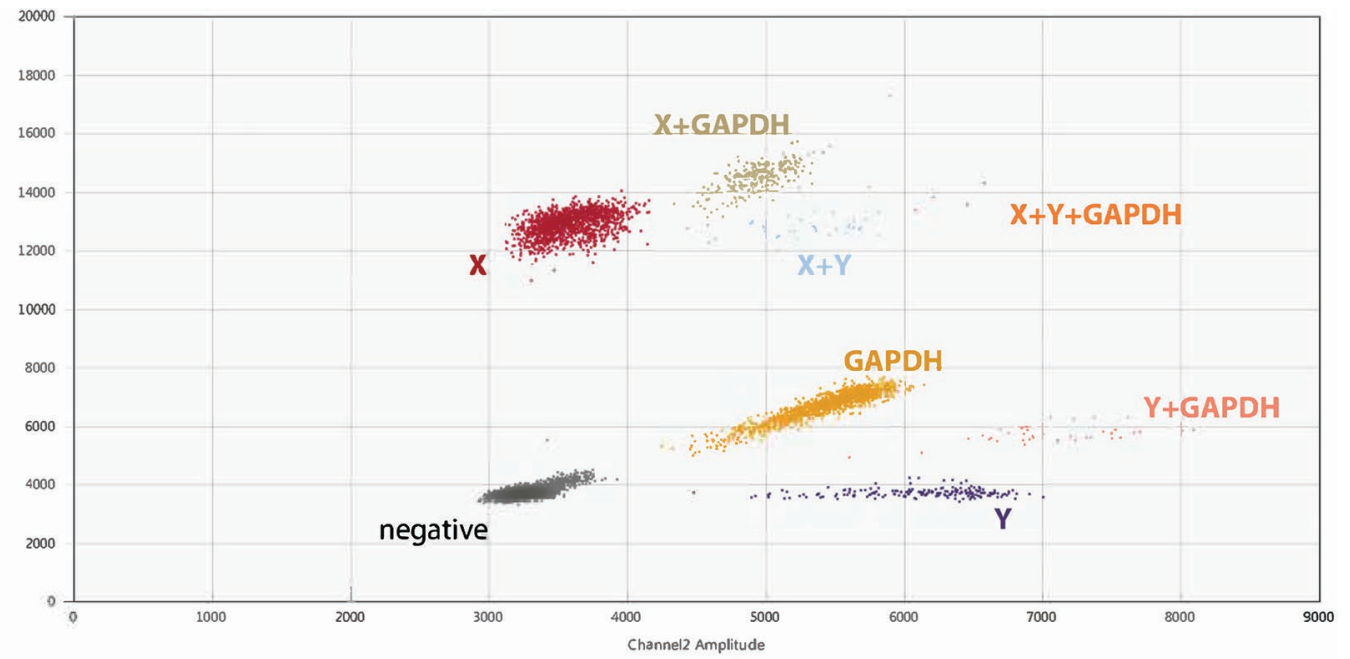

C

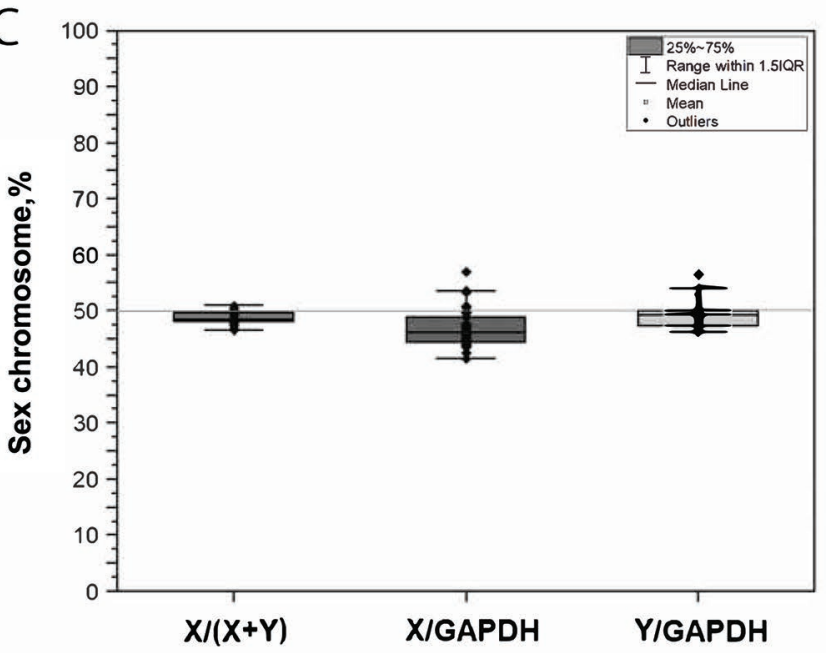

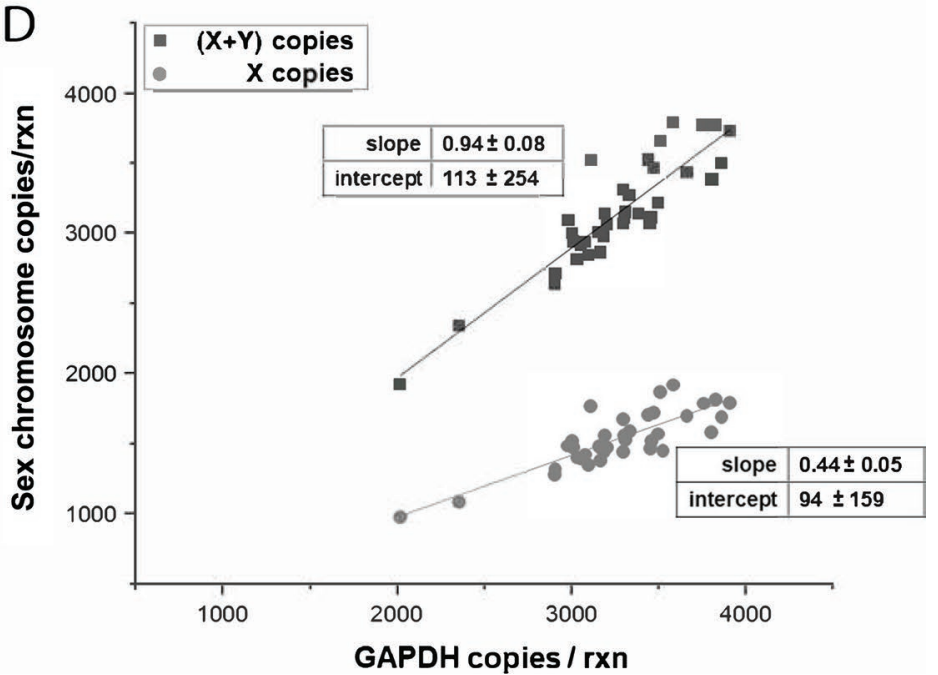

Figure 2. Optimized droplet digital PCR (ddPCR) sex skew assay chemistry. (A) Schematic representing primer and probe combinations in which the $\mathrm{X}$ chromosome is reported by a FAM-labeled probe, Y chromosome by a HEX-labeled probe, and GAPDH by a mixture of FAM- and HEX-labeled probes. (B) Scatterplots of fluorescent signal from droplets from the triplex sex skew ddPCR assay interrogating 12 ng of genomic template DNA with $900 \mathrm{n} M$ primer and $250 \mathrm{n} M$ probe for $G A P D H$ and the X chromosome, and 1,300 $\mathrm{n} M$ primer and $350 \mathrm{n} M$ probe for the $\mathrm{Y}$ chromosome. Droplet populations are labeled as follows: $\mathrm{X}$ chromosome FAM $=$ red, $\mathrm{Y}$ chromosome HEX $=$ purple, GAPDH HEX $+\mathrm{FAM}=$ yellow, dual-occupancy $\mathrm{X}+G A P D H=\tan , \mathrm{X}+\mathrm{Y}=$ light blue, $\mathrm{Y}+G A P D H=$ salmon, triple occupancy $\mathrm{X}+\mathrm{Y}+G A P D H=$ orange, and droplets lacking fluorescent signal (negative) = gray. (C) Boxplot showing the percent sex chromosome distribution in genomic DNA isolated from frozenthawed conventional semen, calculated as $\mathrm{X} /(\mathrm{X}+\mathrm{Y}), \mathrm{X} / G A P D H$, and $\mathrm{Y} / G A P D H$, for $\mathrm{n}=40$ unique Holstein sires. All 3 calculations revealed a 50/50 sex chromosome ratio. (D) Scatterplot of GAPDH copies counted per reaction (rxn) versus sex chromosome copies per reaction revealed a linear slope of $0.94 \pm 0.08$ for $(\mathrm{X}+\mathrm{Y})$, demonstrating that the autosomal marker tallied the same total number of cells as the additive sum of $\mathrm{X}+\mathrm{Y}$ copies. The linear slope for GAPDH versus $\mathrm{X}$ chromosome copies/reaction was $0.44 \pm 0.05$, consistent with a predicted $50 \% \mathrm{X}$ chromosome distribution in conventional semen. 
$125 \mathrm{n} M$ probe for $G A P D H$ (split equally between FAMand HEX-labeled probes), $900 \mathrm{n} M$ primer with $250 \mathrm{n} M$ FAM probe for the $\mathrm{X}$ chromosome, and 1,300 n $M$ primer with $350 \mathrm{n} M$ HEX probe for the $\mathrm{Y}$ chromosome in a 24$\mu \mathrm{L}$ reaction containing $12 \mu \mathrm{L}$ of $2 \times$ ddPCR Supermix for Probes (Bio-Rad Laboratories), $0.5 \mu \mathrm{L}$ of BamHIHF (high-fidelity preparation of the BamHI restriction enzyme, New England Biolabs, Ipswich, MA), $0.5 \mu \mathrm{L}$ of $2 \mu M$ dNTPs, and $12 \mathrm{ng}$ of genomic DNA template. Droplets were generated using an automated droplet generator with automated droplet generation oil (BioRad Laboratories). Thermocycling was performed in a Bio-Rad C100 Touch Thermal cycler as follows: $10 \mathrm{~min}$ at $95^{\circ} \mathrm{C}, 40$ cycles of $\left(30 \mathrm{~s}\right.$ at $94^{\circ} \mathrm{C}$ and $60 \mathrm{~s}$ at $\left.60^{\circ} \mathrm{C}\right)$, and then $10 \mathrm{~min}$ at $98^{\circ} \mathrm{C}$, followed by a $4^{\circ} \mathrm{C}$ indefinite hold, with a ramp rate of $2^{\circ} \mathrm{C} / \mathrm{s}$. The QX200 Droplet Reader (Bio-Rad Laboratories) was used to count droplets and quantify fluorescent signal per droplet. Amplicon copies/reaction and copies/microliter were quantified using QuantaSoft and Analysis Pro software (Bio-Rad Laboratories, version 1.7.4.0917). Figure 2B shows an example fluorescent scatterplot from a single assay well run under optimized conditions such that $\geq 1,000$ cells were interrogated; droplet populations identified on the scatterplot demonstrate clear separation. To verify the optimized chemistry, genomic DNA from conventional bovine semen straws was analyzed to determine whether the ddPCR sex skew assay consistently reported the expected $\sim 50 / 50 \mathrm{X} / \mathrm{Y}$ chromosome ratio. The percentage of each sex chromosome amplicon was quantified as a function of either total $\mathrm{X}+\mathrm{Y}$ amplicons or total autosomal (GAPDH) amplicons from $\mathrm{n}$ $=40$ Holstein sires, with each sample run in triplicate. Figure $2 \mathrm{C}$ demonstrates that $\mathrm{X}$ and $\mathrm{Y}$ chromosome amplicon representation equaled $50 \%$ when calculated as $\mathrm{X} /(\mathrm{X}+\mathrm{Y}), \mathrm{X} / G A P D H$, or $\mathrm{Y} / G A P D H$. Figure 3D plots $G A P D H$ copies quantified versus total quantified $(\mathrm{X}+\mathrm{Y})$ copies; a linear slope of $0.94 \pm 0.08 \mathrm{dem}$ onstrates that the total number of sex chromosomes counted was equal to the number of autosomal GAPDH copies counted. Figure 2D also plots GAPDH copies counted versus $\mathrm{X}$ chromosome copies counted, where a slope of $0.44 \pm 0.05$ corresponds to $50 \% \mathrm{X}$ chromosome distribution in conventional semen. These data from conventional semen confirmed that the ddPCR sex skew assay reported the expected sex chromosome distribution across all genomic templates (sires) tested, and interrogated sufficient cells to meet statistical rigor requirements.

To validate the cell counting accuracy of the ddPCR assay for genomic DNA from sexed semen, both the 1:1 $G A P D H:(\mathrm{X}+\mathrm{Y})$ copy ratio and $G A P D H$ copy number prediction accuracy were confirmed by assaying genomic DNA isolated from the viable sperm population in frozen-thawed sex-skewed semen straws. Given the unique nature of IntelliGen X skew sexed semen (ABS Global Inc., DeForest, WI), which contains laser-sliced cells predominantly comprising Y-chromosome-bearing sperm, careful attention was paid to sample cleanup before genomic DNA extraction. If DNA is extracted from a frozen-thawed sexed-semen sample without removing the laser-killed cells, the predicted result is an apparent $50 / 50 \mathrm{X} / \mathrm{Y}$ chromosome representation. This does not, however, reflect the viable, motile population of cells that may ultimately produce a pregnancy. Standard cleanup protocols were used to eliminate nonviable sperm from the sample before genomic DNA extraction as follows. For each individual genomic DNA sample, sperm from 2 frozen-thawed sexed-semen straws or 1 frozen-thawed conventional semen straw (Genus, ABS Global) were centrifuged for $10 \mathrm{~min}$ at $300 \times g$ through a Bovipure gradient $(0.5 \mathrm{~mL}$ of $40 \%$ layered over 0.5 $\mathrm{mL}$ of $80 \%$; Nidacon International AB, Mölndal, Sweden). Cells from sexed-semen straws generated by laser ablation technology (IntelliGen, Genus, Windsor, WI) were then run through a glass wool column $[0.03 \mathrm{~g}$ of glass wool borosilicate (112X-475, JohnsManville, Denver, $\mathrm{CO}$ ) in a 1-mL syringe packed to a volume of 0.1 $\mathrm{mL}$ ] by gravity drip to remove nonviable cells. Cells were lysed in buffer $(50 \mathrm{~m} M$ potassium chloride, $10 \mathrm{mM}$ Tris base, $\mathrm{pH} 8.3,2.5 \mathrm{~m} M$ magnesium chloride, $0.5 \%$ Tween-20, $1 M$ dithiothreitol, $1 \mu \mathrm{g} / \mu \mathrm{L}$ RNase A, and $40 \mathrm{mg} / \mathrm{mL}$ proteinase $\mathrm{K}$ ) for $18 \pm 1 \mathrm{~h}$ at $37^{\circ} \mathrm{C}$ with constant rotation, followed by $1 \mathrm{~h}$ at $55^{\circ} \mathrm{C}$ with constant rotation. Genomic DNA was purified using the Agencourt DNAdvance Kit (Beckman Coulter, Indianapolis, IN) per the manufacturer's instructions, mixing $200 \mu \mathrm{L}$ of lysate with $75 \mu \mathrm{L}$ of Bind 1 and $40 \mu \mathrm{L}$ of Bind 2 buffer (containing magnetic beads) for $5 \mathrm{~min}$ at $750 \mathrm{rpm}$ at $24^{\circ} \mathrm{C}$. Samples were placed on the magnetic platform for 4 min to allow the magnetic DNA-binding beads to move to the magnet, and the unbound lysate fraction was removed from the wells. Beads bound to DNA were washed 3 times with $150 \mu \mathrm{L}$ of $75 \%$ ethanol, shaking 5 min at $850 \mathrm{rpm}$ at $24^{\circ} \mathrm{C}$ for each wash, followed by $4 \mathrm{~min}$ on the magnet before removing wash fraction from the beads. Then DNA was eluted in $25 \mu \mathrm{L}$ of supplied elution buffer, with shaking for $10 \mathrm{~min}$ at 1,200 rpm at $37^{\circ} \mathrm{C}$. Samples were placed on the magnet for 4 min before transferring the eluted DNA to a new tube. The concentration of DNA was quantified on a nanophotometer (Implen GmbH, Munich, Germany). Genomic DNA from frozen-thawed sexed-semen straws representing 220 sires (including Holstein, Jersey, and Angus) was analyzed using the ddPCR sex skew assay and confirmed a 1:1 linear relationship between GAP$D H$ and $(\mathrm{X}+\mathrm{Y})$ counts per reaction was maintained (Supplemental Figure S2A; https://doi.org/10.3168/ 


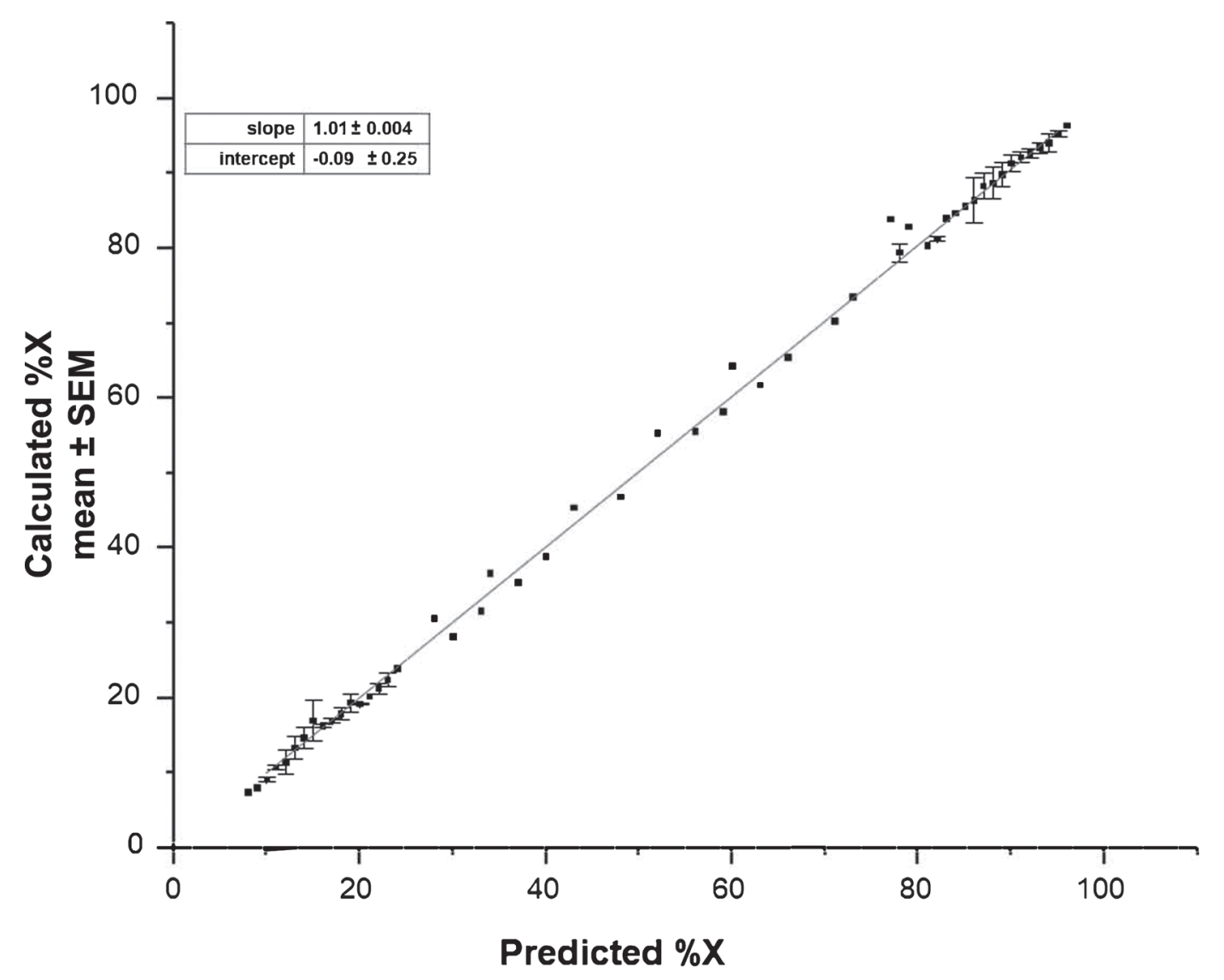

Figure 3. Titrating X-skewed and Y-skewed genomic DNA samples demonstrated that the droplet digital PCR (ddPCR) sex skew assay quantified percentage X $(\% \mathrm{X})$ with a linear dynamic range from 10 to $95 \%$. The plots show predicted versus calculated $\% \mathrm{X}$ from $\mathrm{n}=6$ experiments that mixed known high X-skew with known high Y-skew genomic bovine DNA to create a stepwise dose-response curve. DNA samples represented $n=12$ bulls. Linear fit slope $=1.01 \pm 0.04$.

jds.2019-17877). The dynamic range for the GAPDH primer/probe set was defined by quantifying the total number of copies counted per triplex ddPCR reaction (X, Y, GAPDH primer/probes) across a range from 0.1 to $27 \mathrm{ng}$ of DNA input from frozen-thawed, sexedsemen straws from 4 sires (2 Jersey, 2 Holstein) read in triplicate reactions. Supplemental Figure S2B plots predicted copy number per reaction against GAPDH copies counted, revealing a slope of 1 when using a Bos taurus genomic molecular weight of $324.22 \mathrm{~g} / \mathrm{mol}$ (Supplemental Figure S2B, slope $=1.02 \pm 0.04$ ) or $349.65 \mathrm{~g} / \mathrm{mol}$ (slope $=0.95 \pm 0.04$, not shown). The linear dynamic range for accurate $G A P D H$ copy counts in the sex skew assay was from 0.3 to $27 \mathrm{ng}$ of genomic DNA/20- $\mu \mathrm{L}$ ddPCR reaction, corresponding to 100 to 9,000 GAPDH copies/reaction.

To determine the input DNA range across which the calculated \% $\mathrm{X}$ exhibited minimal variance and provided a precise value for the calculated $\% \mathrm{X}$ (or $\% \mathrm{Y}$ ) chromosome, sex skew was quantified as a function of DNA input in nanograms. Supplemental Figure S3A (https://doi.org/10.3168/jds.2019-17877) plots apparent \% X as a function of input DNA (ng), and demonstrated that the calculated $\% \mathrm{X}$ did not change for a template input ranging between 9 and $27 \mathrm{ng}$ of total genomic DNA per reaction, exhibiting a standard error $<1 \%$ (error propagated from duplicate sexed-semen samples from $n=4$ unique sires). The apparent $\% X$ decreased when input DNA was $<3 \mathrm{ng}$, such that the apparent skew value was statistically different for 0.3 and $0.1 \mathrm{ng}$ of genomic DNA compared with the stable assay range (one-way ANOVA, $P<0.05$, Bonferroni means comparison). These data demonstrate that the sex skew assay reported reproducible $\mathrm{X}$ skew from 9 to $27 \mathrm{ng}$ of input genomic DNA. The $\mathrm{X}$ skew was then calculated in repeat measures for genomic template from frozen-thawed sex-skewed straws representing 20 sires. Supplemental Figure S3B plots the calculated $\% \mathrm{X}$ from quadruplicate assays. The average standard deviation in repeat measures was 0.5 percentage points, demonstrating that under these conditions, the ddPCR sex skew assay reports the $\mathrm{X}$ skew $\pm 0.5 \%$, making the 
assay the most precise measurement of sex skew currently available.

Although repeat measures showed tight variance, we chose to improve the ddPCR sex skew robustness by building the following assay requirements: each replicate assay well must interrogate at least 1,000 cells (where the assay is performed in duplicate) to ensure sufficient sample size; the number of autosomal $(G A P D H)$ copies quantified must equal $(\mathrm{X}+\mathrm{Y})$ within-assay variance; and the absolute copy number across replicate wells must exhibit $<10 \%$ variance. Supplemental Figure S4 (https://doi.org/10.3168/jds.2019-17877) presents total GAPDH counts from duplicate reactions as mean $\pm \mathrm{SD}$ for $\mathrm{n}=220$ unique sex-skewed straw batches. Samples that met both the minimum interrogation threshold and variance criteria are shown as filled squares. Samples that met count criteria but exhibited variance outside the acceptable range are shown as open circles, and samples that failed to meet total interrogated cell criteria are shown as filled triangles. This figure demonstrates our ability to flag samples that fail to meet stringent assay requirements so they may be reevaluated.

The sex skew assay demonstrated elegant precision in repeat measures and accuracy when quantifying genomic DNA from conventional (non-sexed) bovine semen straws. To define the precision of the assay across a range of sex skews (varying the expected \%X), genomic DNA template from samples of known $\mathrm{X}$ or $\mathrm{Y}$ skew (where starting skew was $\geq 90 \% \mathrm{X}$ or $\mathrm{Y}$, respectively) were mixed in a dose-response manner to span 10 to $95 \% \mathrm{X}$. Figure 3 plots the predicted versus calculated \%X from $\mathrm{n}=5$ dose-response template mixtures (representing a total of 10 sires). These data reveal a linear fit with a slope of $1.01 \pm 0.004$ (Figure 3 ), demonstrating that even at very low $\mathrm{X}$ amplicon counts $(10 \% \mathrm{X}, 90 \% \mathrm{Y})$, the assay provides accurate skew quantification.

To determine whether the $\mathrm{X}$-skew data reflect the customer experience, sex skew was quantified from commercially available (ABS Global) sexed semen from 2017 and compared with the historical customer experience of female calves born from sexed-semen inseminations from 2012 to 2017. Figure 4A plots the distribution of female calves born from 2012 to 2017 from inseminations using sexed semen from the Real World Database $($ mean $=84.0 \%$ female calves, $\mathrm{n}=$ 168 records, where each record represents data from 1 sire from all farms reporting $\geq 100$ births for that sire from a total of 294,732 birth records; https:/ /www .absglobal.com/services/real-world-data/). Figure 4B plots the histogram of the sex skew from commercial Sexcel (ABS Global) sexed semen as reported by the ddPCR assay $($ mean $=88.6 \% \mathrm{X}$ chromosome, $\mathrm{n}=115$, representing 63 Holstein and 52 Jersey in 629 straw batches dated 17011-17118). Although the data do not represent paired sampling, the histograms demonstrate that the ddPCR sex skew assay of commercially available sexed bovine semen generally reflected the historical customer experience of female calves born.

To date, the ddPCR sex skew assay has been used to quantify the percentage of X-chromosome-containing cells in sexed semen from 24 Angus, 22 Brown Swiss, 5 Hereford, 13 Kobe, 120 Jersey, 616 Holstein, and 15
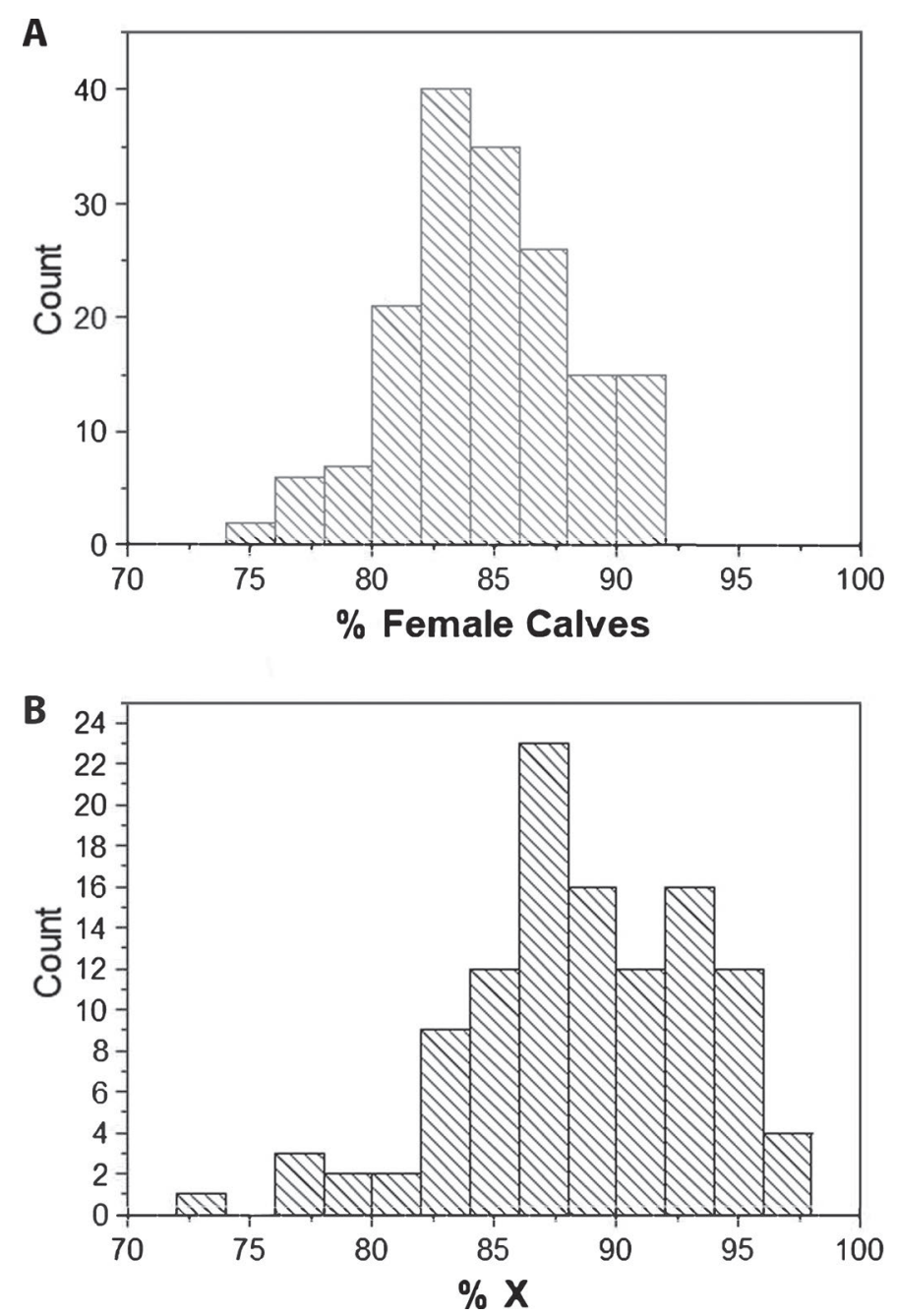

Figure 4. Droplet digital PCR (ddPCR) sex skew assay correlated with historical field-reported female calves born from sexed semen. (A) Histogram depicts the percentage of female calves born from sexedsemen inseminations from 2012 to 2017 , with mean $=84.0 \%$ female calves, minimum $=74 \%$, maximum $=91 \%$. Each count represents a data record from at least 100 births/sire per farm. (B) Histogram depicts \%X chromosome sperm in commercial sexed-semen straw batches from Julian dates $17011-17188(\mathrm{n}=115$ straw batches $)$, with mean $=$ $88.6 \% \mathrm{X}$ chromosome, minimum $=72.7 \%$, maximum $=96.5 \%$. These data are not paired with those of panel A. These data show that the sex skew assay results correspond with the historical distribution of female calves born from sexed-semen inseminations. 
other assorted beef breed sires, demonstrating that the assay is relatively insensitive to background genetic variation and can be successfully applied across Bos taurus breeds. This precise, sensitive sex skew assay with a wide dynamic range and robust reproducibility represents an orthogonal testing methodology for independent labs. It should provide customers with confidence in the product they are purchasing, may facilitate market definitions for differential skew products, and may have unique applications for difficult-tosex species.

\section{ACKNOWLEDGMENTS}

The authors have not stated any conflicts of interest.

\section{REFERENCES}

Borchersen, S., and M. Peacock. 2009. Danish A.I. field data with sexed semen. Theriogenology 71:59-63. https://doi.org/10.1016/j .theriogenology.2008.09.026.

Cerchiaro, I., M. Cassandro, R. Dal Zotto, P. Carnier, and L. Gallo. 2007. A field study on fertility and purity of sex-sorted cattle sperm. J. Dairy Sci. 90:2538-2542. https://doi.org/10.3168/jds .2006-694.

Faust, M. A., J. Betthauser, A. Storch, and S. Crego. 2016. Effects for fertility of processing steps of a new technology platform for producing sexed sperm. J. Anim. Sci. 94(Suppl_5):544.

Habermann, F. A., A. Winter, I. Olsaker, P. Reichert, and R. Fries. 2005. Validation of sperm sexing in the cattle (Bos taurus) by dual colour fluorescence in situ hybridization. J. Anim. Breed. Genet. 122(Suppl 1):22-27. https://doi.org/10.1111/j.1439-0388 .2005.00488.x.

Healy, A. A., J. K. House, and P. C. Thomson. 2013. Artificial insemination field data on the use of sexed and conventional semen in nulliparous Holstein heifers. J. Dairy Sci. 96:1905-1914. https:// doi.org/10.3168/jds.2012-5465.

Heid, C. A., J. Stevens, K. J. Livak, and P. M. Williams. 1996. Real time quantitative PCR. Genome Res. 6:986-994. https://doi.org/ 10.1101/gr.6.10.986.

Johnson, L. A. 1995. Sex preselection by flow cytometric separation of $\mathrm{X}$ and $\mathrm{Y}$ chromosome-bearing sperm based on DNA difference: A review. Reprod. Fertil. Dev. 7:893-903. https://doi.org/10.1071/ RD9950893.

Johnson, L. A., and G. R. Welch. 1999. Sex preselection: High-speed flow cytometric sorting of $\mathrm{X}$ and $\mathrm{Y}$ sperm for maximum efficiency. Theriogenology 52:1323-1341. https://doi.org/10.1016/S0093 $-691 X(99) 00220-4$.

Kawarasaki, T., G. R. Welch, C. R. Long, M. Yoshida, and L. A. Johnson. 1998. Verification of flow cytometrically-sorted X- and
Y-bearing porcine spermatozoa and reanalysis of spermatozoa for DNA content using the fluorescence in situ hybridization (FISH) technique. Theriogenology 50:625-635. https://doi.org/10.1016/ S0093-691X(98)00167-8.

Khamlor, T., P. Pongpiachan, S. Sangsritavong, and N. Chokesajjawatee. 2014. Determination of sperm sex ratio in bovine semen using multiplex real-time polymerase chain reaction. Asian-Australas. J. Anim. Sci. 27:1411-1416. https://doi.org/10.5713/ajas.2014 .14223 .

Lalande, M. E., and R. G. Miller. 1979. Fluorescence flow analysis of lymphocyte activation using Hoechst 33342 dye. J. Histochem. Cytochem. 27:394-397. https://doi.org/10.1177/27.1.86569.

Moruzzi, J. F. 1979. Selecting a mammalian species for the separation of X- and Y-chromosome-bearing spermatozoa. J. Reprod. Fertil. 57:319-323. https://doi.org/10.1530/jrf.0.0570319.

Norman, H. D., J. L. Hutchison, and R. H. Miller. 2010. Use of sexed semen and its effect on conception rate, calf sex, dystocia, and stillbirth of Holsteins in the United States. J. Dairy Sci. 93:38803890. https://doi.org/10.3168/jds.2009-2781.

Parati, K., G. Bongioni, R. Aleandri, and A. Galli. 2006. Sex ratio determination in bovine semen: A new approach by quantitative real time PCR. Theriogenology 66:2202-2209. https://doi.org/10 .1016/j.theriogenology.2006.07.007.

Puglisi, R., R. Vanni, A. Galli, D. Balduzzi, K. Parati, G. Bongioni, G. Crotti, R. Duchi, C. Galli, G. Lazzari, and R. Aleandri. 2006. In vitro fertilisation with frozen-thawed bovine sperm sexed by flow cytometry and validated for accuracy by real-time PCR. Reproduction 132:519-526. https://doi.org/10.1530/rep.1.01173.

Rens, W., F. Yang, G. Welch, S. Revell, P. C. O'Brien, N. Solanky, L. A. Johnson, and M. A. Ferguson Smith. 2001. An X-Y paint set and sperm FISH protocol that can be used for validation of cattle sperm separation procedures. Reproduction 121:541-546. https:// doi.org/10.1530/rep.0.1210541.

Roti Roti, E., N. Cray, M. Wagner, and M. R. Botts. 2018. Methods and systems for assessing and/or quantifying sperm cell subpopulations bearing a specific genetic signature. Genus PLC, Basingstoke, UK, 20190071725.

Seidel, G. E. Jr. 2014. Update on sexed semen technology in cattle. Animal 8(Suppl 1):160-164. https://doi.org/10.1017/ S1751731114000202.

van Munster, E. B., J. Stap, R. A. Hoebe, G. J. te Meerman, and J. A. Aten. 1999. Difference in volume of X- and Y-chromosomebearing bovine sperm heads matches difference in DNA content. Cytometry 35:125-128. https://doi.org/10.1002/(SICI)1097 -0320(19990201)35:2<125::AID-CYTO3>3.0.CO;2-H.

\section{ORCIDS}

Nicole Cray ำ https://orcid.org/0000-0002-6377-6565 Jami Hauer @ 1 https://orcid.org/0000-0001-9811-971X Elon Roti Roti $\odot$ https://orcid.org/0000-0002-0526-9223 